\title{
Analysis of the reasons for the regular practice of physical activity in the return of injuries of amateur Volleyball athletes
}

\author{
Luciana Botelho Ribeiro', Ivan Wallan Tertuliano 1,2, Flávio Rebustini',3, Priscila Carneiro Valim-Rogatto4, \\ Afonso Antonio Machado
}

\begin{abstract}
Background: Motivation is an important variable for sports performance. It is important because it is a psychological variable that coordinates and directs the intensity and direction of the individuals' efforts in the activity to be performed. In this way, studying it, as a variable that interferes in the performance of athletes is of paramount importance. Objective: To investigate the reasons of injured volleyball athletes to return to regular practice of their activities. Method: The research was carried out using an sequential exploratory, mixed method. IMPRAF-54 and the Focus Group technique were used. The Inventory of Motivation for the Regular Practice of Physical Activity (IMPRAF-54) evaluates the reasons for the practice of regular physical activity, distributed in six different processes. Thus, in the first phase, 32 amateur volleyball players of the juvenile and adult categories, of both genders, with a mean age of 35.45 years participated in the study. After the participants answered the questionnaire, the Focus group was formed with 10 athletes, who participated in the second part of the study. These athletes participated in four meetings to discuss the dimensions posed by the researchers, in an attempt to observe if the athletes interpreted the dimensions of IMPRAF-54 in ways similar to that expected by the instrument. Results: The results showed that athletes were motivated in the dimension of pleasure, health and sociability. In the Focus group, the results reinforced the data of the IMPRAF 54, in addition, this phase allowed to explore the perceptions of the sensations and the feelings of the athletes while injured. Conclusion: It is possible to state that while amateur athletes are recovering from injuries, the focus is not competition. Knowledge of these results may aid in the type of psychological work that can be performed while athletes are injured.
\end{abstract}

Keywords: Injuries. Human Development. Motivation. Emotional States.

\section{INTRODUCTION}

Motivation is a psychological variable that coordinates and directs the intensity and direction of the individuals' efforts in the activity to be performed and it is subdivided into three factors: intrinsic motivation, extrinsic motivation and amotivation ${ }^{1}$. Intrinsic motivation is influenced by situations and experiences already experienced and the current emotional state of the subject. Extrinsic motivation is influenced by external factors in the performance of individuals' activities. And the subjects with amotivation, has no motivation whatsoever that influences them to look for any activity $^{2,3}$. However it is worth emphasizing that the subject being extrinsically motivated does not mean negative behavior. The extrinsic motives have a certain degree of autonomy and the intrinsic ones are self-determining ${ }^{4}$. Many theories study motivation, but one of the most accepted and widespread in the literature is the Self-Determination Theory (SDT) $)^{4-6}$. The basis of SDT is that the human being is active and directed to grow and develop in the sense of the self, integrating with the environment and its structures ${ }^{7,8}$. This depends on three social factors: autonomy, interaction with the environment and competence to perform the activity. The subject must be able to deal with these interferences, since they will result in the observable behaviors and socially practiced in groups and in individual actions ${ }^{3}$. Thinking about the SDT, the three social factors can be influenced after the injury as well as in the rehabilitation period since the autonomy is reduced because it is not possible to exercise by free choice, in addition, long periods outside the training do not allow interaction with the group and the perception of competence become impaired ${ }^{4,9}$. In the sporting context, there are high emotional levels that consequently arouse diverse feelings in the people involved. A single situation in sport can be faced in different ways by each subject which makes this confrontation part of its specifics. The athletes exposes themselves to constant vulnerability in the sport needing physical and psychological preparation. The imbalance culminates in the appearance of several alterations such as the injury ${ }^{10}$. 
The causes of the lesions can be classified as primary or secondary: the primary causes are immediate causes of the lesions, classified as physiological (fracture, distension, among others) and secondary ones are psychological causes (apathy, depression ${ }^{11}$. There are a number of sources of psychological stress that include fear and failure, excessive competitions, unadapted training for athletes, negative work environment, coaching philosophy, results collection, and self-control ${ }^{12}$. Studies carried out with the volleyball modality show a greater number of injuries resulting from the overload of training leading to the decrease of the performance of the athletes during the competitions ${ }^{13}$. Sports injuries can be defined as occupational accidents that come as a consequence of sports activity and may have physiological and psychological causes. The lesion undergoes variations according to cause, intensity and time. These variables influence the recovery process. The injuries can cause the athlete to abandon their daily routine and this change of behavior brings with it other unfavorable factors ${ }^{14}$. A high training load influences the athlete's emotional states, resulting in impaired concentration, reduced attention, increased reaction time, changes in the subjective state, immunological and mood changes, causing illnesses such as sports injuries, depression and anxiety ${ }^{15}$. Investigating the reasons for returning to regular physical activity becomes relevant in addition to considering individual aspects of the athletes to return to sports practice. Such aspects should be included in the decision to adaptations of training loads since these and other factors may also indirectly influence the athlete and his teams. Thus, the objective of this study was to investigate the motives of volleyball athletes to return to regular practice of activities while injured.

\section{METHOD}

\section{Participants}

The sample was selected in a non-random way using netnography in social networks and e-mails. Netnography can be defined as the study of subjects or communities in the virtual environment, similar to ethnography, but faster, simpler, inexpensive and less invasive ${ }^{16}$. In the first phase, the sample consisted of 32 amateur volleyball players of the juvenile and adult categories, of both genders ( 25 females and 7 males). The mean age of the participants was $37.9( \pm 9.33)$ years for female and $33( \pm 13.58)$ years for the male. The inclusion criteria of the research were: to be over 18 years of age, to be a volleyball practitioner and to have suffered a self-reported sports injury. Not being more interested in participating in the study was considered as the criterion of exclusion. For selection and organization of the Focus Group (FG), it was essential to be clear about the inclusion criteria of the research subjects. The group consisted of ten athletes who had answered the questions and who were interested, after prior consultation, to compose this part of the study. The formation of the FG was intentional and should have at least one point of similarity between the participants, which was already assured, given the fact that they are part of the previously contacted the group and with which already had collected the data of the issues described quantitatively. The second phase consisted of 10 subjects from the first phase, three males and seven females. The mean age of participants was $35( \pm 15.52)$ years for males and 32.7 ( \pm 14.04$)$ years for females. The study followed all the ethical procedures required by the Ethics Committee in Research with Human Beings of the Institute of Biosciences of Unesp of Rio Claro/SP and was approved under no. 086/2013. All these procedures were performed in the virtual environment, that is, by e-mail. Thus, the free informed consent form (FICF) was made available via electronic platform, which should be filled out and, at the end of the filling, the participant should click on the option "I accept all the conditions above" to continue the research, accepting all the conditions established in the FICF.

\section{Procedures}

The research was guided by the sequential explanatory, mixed method with netnographic emphasis (in virtual environments). The use of mixed methods is justified by the complexity of the social world, which requires a more interrelated understanding of philosophical paradigms (assumptions about the social world and the nature of knowledge), methodological (the logic of inquiry) and methods (collection of data techniques) ${ }^{17}$. Currently the mixed methods are centered on six models: a) convergent parallel; b) explanatory sequential; c) exploratory sequential; d) incorporated; e) transformative and; f) multiphase. In the mixed research method, there are possibilities to research several qualitative and quantitative elements with great comprehensiveness and depths of understanding and verification. According to Tashakkori \& Creswell ${ }^{18}$, the researcher collects and analyzes the data, integrates the findings and extracts inferences using qualitative and quantitative approaches or methods in a single study or research program, thus, this method supplies greater needs to meet the results by enabling a more complete analysis of the data ${ }^{19}$. The explanatory sequential method used in the research has utility when the researcher intends to evaluate trends and relationships next to the quantitative data, but also to be able to explain why this phenomenon happen ${ }^{20}$. In accordance with the explanatory sequential model, the data were initially explored quantitatively, trying to describe some meanings that can be considered inherent to the objects and acts, being thus classified as objective. In this type of approach the data collection is performed through the obtaining of structured answers and the analysis techniques are deductive and oriented by the results. In this first phase of the study was applied the Inventory of Motivation for the Regular Practice of Physical Activity (IMPRAF-54) ${ }^{21}$. The inventory 
evaluates the motivation, through 54 corresponding items, the reasons for the practice of regular physical activity distributed in six dimensions: Stress control, Health, Sociability, Competitiveness, Aesthetics and Pleasure. These scales are distributed in nine blocks, the last to verify the degree of agreement between the first and second responses related to the same item. The answers of the subjects are given by means of a scale of the type Likert, graduated in five points, being (1) this motivates me very little and (5) this motivates me very much. The scoring of each dimension can vary from 8 (poorly motivated) to 40 points (highly motivated). The IMPRAF-54 was adapted to Google Drive ${ }^{\circledR}$ and the link was sent to the technicians to send to their athletes by email. The instrument remained available for responses for one month after the link was sent.

Then, qualitative data were collected and analyzed to complement the quantitative data using the $\mathrm{FG}$ technique ${ }^{20}$ in which only participated 10 athletes of the first phase who were interested in participating in the Facebook ${ }^{\circledR}$ group, following the methodological orientation of studies that indicate from six to fifteen people as a recommendable module ${ }^{22}$. The athletes in the second phase participated in four meetings (90 minutes each) to discuss the dimensions placed by the investigator on Facebook ${ }^{\circledR}$, in a transposed language, in an attempt to observe if the athletes interpreted the dimensions of IMPRAF-54 in different ways that described in addition to allowing an open moment of discussion that would provide the opportunity for new information, allowing the researcher not only to examine the different people's analyzes in relation to a theme but to explore how the facts are articulated, confronted and altered through group interaction and also how this relates to peer communication and group norms $\mathrm{s}^{23}$. In this environment, FG provides relaxation for participants to answer group questions, facilitating the formation of new and original ideas; to generate possibilities contextualized by the study group itself; to interpret beliefs, values, concepts, conflicts and points of view, and also to understand the theme in everyday life.

\section{Statistical analysis}

The IMPRAF-54 data were analyzed using descriptive statistics by the IBM Statistical Package for the Social Sciences (SPSS 18 software, Chicago, USA). Statistical analysis was performed using central tendency (mean and trimmed mean), dispersion (standard deviation), minimum and maximum score and sample distribution (interquartile range) and the Shapiro Wilk test (SW) to test the normality of the sample distribution, together with the indices of asymmetry and flatness. To verify possible effects of extreme values on the means, a " $\mathrm{t}$ " test was performed for a sample using the trimmed mean of each dimension as a reference. The Pearson Correlation test was performed to evaluate the association between the dimensions. To evaluate the existence of significant differences between the mean variance of the dimensions, an Anova with repeated measurements was performed taking the dimensions as variables among subjects with post hoc Bonferroni test to control any type I error with $p<0.05$. In the mixed research method, there are possibilities to research several qualitative and quantitative elements with great comprehensiveness and depths of understanding and verification ${ }^{17}$. The researcher collects and analyzes the data, integrates the findings and extracts inferences using qualitative and quantitative approaches or methods in a single study or research program ${ }^{18-20}$.

\section{Qualitative analysis}

The data of the FG were analyzed from the "Content Analysis" divided into three phases: a) For the pre-analysis was made the choice of the documents submitted for analysis, the formulation of the hypotheses and objectives that will elaborate the indicators to support the final interpretation; b) the exploitation of the material consisted in the codification or enumeration according to the rules previously determined; c) treatment of the results obtained and the interpretation that can also serve as a basis for another analysis. In this last phase results are obtained that can propose inferences and advance interpretations of the objectives ${ }^{18}$. A reading of the statements was carried out initially, followed by the indexation of the data, which consists in the ordering and categorization of the same, from the highlight of recurrent themes. This indexation is inductive and the categories of analysis were grouped by affinity and composed the following descriptor themes: motivation for physical activities, health, emotions, group of friends, physical-mental recovery and satisfaction. After the categorization of the data, were used the Content Analysis to raise the descriptor themes, which were submitted to a specific analysis, with the re-reading of each category and signaling construction of its descriptors, whose immersion allowed the deepening and analytical understanding. At the end, the data interpretation and the approximation with the authors that subsidized the theoretical reference of the study were performed. The categories provided a priori were established based on the SDT, as these hypotheses help to guide the process and the organization of the data ${ }^{20}$.

\section{RESULTS}

The results are presented in two application phases, the first is the IMPRAF-54 and the second is the Focal Group.

\section{First Phase - Aplication of the IMPRAF 54}

The dimensions that motivated the injured athletes to practice physical activity were "Pleasure" followed, respectively, by "Health", "Sociability", "Stress Control", "Aesthetics" and "Competitiveness". Table 1 shows the mean values of subjects in the IMPRAF-54.

Based on the results of the averages of subjects in the dimensions, we can say that they had a tendency to 
maintain their mean values in relation to the minimum (8) and maximum (40) values. Analyzing the asymmetry of the data $(-1.96<$ Asymmetry/EPs $<1.96)$ and flattening of the distribuitions $(-1.96<$ Kurtosis/EPK $<1.96)$ indicate that the dimensions Health, Sociability and Pleasure presented an asymmetric distribution negative, indicating the curve for the maximum values, even if they are not symmetrical, these dimensions are mesocurtic. The dimensions of Stress Control, Competitiveness and Aesthetics presented symmetrical and mesocuric distributions. The values of the trimmed means are not significantly different from the values of the arithmetic means, in this way it is possible to affirm that the values at the extremes of the scale do not interfere in a significant way in the composition of the average. The analysis of variance between the dimensions of the instrument pointed to the existence of significant differences in the variance of the means presenting the following result for the multivariate $F$ model $(5.27)=11.007 ; p<0.001 ; \lambda$ Wilks $=0.329 ;$ partial $\eta^{2}=0.69$. The Post Hoc Test of Bonferroni identified that only the Competitiveness dimension did not present significant differences for the variance of the averages of the Aesthetic dimension. Besides these differences, differences of the Aesthetic dimension were found for the Health, Pleasure and Sociability dimensions. It should be noted that the Competitiveness only showed significant correlation with Aesthetics, which is the only one not to present significant difference with the Competitiveness.
Table 2 presents the Pearson correlation results corrected by the Bonferroni technique to avoid the existence of Type I Errors $^{24}$. The results indicate that there are strong, positive and significant correlations of the Health dimension for Pleasure and Stress Control; between Pleasure and Aesthetics and, between Competitive and Aesthetic. It is also pointed out that only 4 of the 15 possible interactions presented significant correlations, already corrected the possible Type I errors, and that the Competitive Dimension only has significant correlation with Aesthetics. This set of associations may indicate that the dimensions operated independently of the results of the other dimensions, effectively measuring different spectra of the analyzed construct.

In the present study, because they are athletes, the Competitiveness dimension should be highlighted, but this was not the case. What we can suggest as hypothesis for this result is that the athletes did not worry so much about the competition for being in rehabilitation.

\section{Second Phase - Focus Group}

The $F G$ is a discussion group that dialogues on a particular topic, by receiving appropriate stimuli for discussion. This technique is distinguished by its characteristics appropriate to the debate and by its own characteristics, mainly by the process of group interaction, which is a result of the data search. In an approaching experience it allows the process of group interaction to develop, favoring exchanges, discoveries

Table 1. Calculations of central tendency, dispersion and distribution of the inventory under study.

\begin{tabular}{|c|c|c|c|c|c|c|c|c|c|c|}
\hline & \multicolumn{6}{|c|}{ Central Tendency and Dispersion } & \multicolumn{4}{|c|}{ Distribuition } \\
\hline & \multirow{2}{*}{ Mean } & \multirow{2}{*}{ sd } & \multirow{2}{*}{$\begin{array}{l}\text { Trimmed } \\
\text { Average }\end{array}$} & \multirow{2}{*}{ Min } & \multirow{2}{*}{ Max } & \multirow{2}{*}{ Interquartile } & \multicolumn{2}{|c|}{ Normality } & \multirow{2}{*}{ Asymmetry } & \multirow{2}{*}{ Flatness } \\
\hline & & & & & & & sw & Sig & & \\
\hline Stress control & 29.40 & 7.52 & 29.79 & 10.0 & 40.0 & 8.75 & 0.94 & 0.09 & -1.37 & $0.27 \stackrel{a}{a}$ \\
\hline Health & 32.03 & 7.68 & 33.50 & 8.0 & 40.0 & 11.75 & 0.86 & 0.00 & -3.04 & 2.08 \\
\hline Sociability & 31.21 & 8.15 & 32.50 & 8.0 & 40.0 & 7.75 & 0.85 & 0.01 & -3.20 & 1.77 \\
\hline Competitiveness & 22.21 & 9.77 & 25.50 & 8.0 & 40.0 & 17.75 & 0.92 & 0.02 & $0.56 \stackrel{a}{a}$ & $-1.58 \stackrel{a}{-}$ \\
\hline Aesthetics & 25.62 & 8.43 & 25.50 & 11.0 & 40.0 & 12.75 & 0.95 & 0.18 & -0.58 a & -1.10 a \\
\hline Pleasure & 32.09 & 7.25 & 34.00 & 8.0 & 40.0 & 7.00 & 0.82 & 0.01 & -3.97 & 3.71 \\
\hline
\end{tabular}

Note: $\mathrm{SD}=$ Standard deviation; Min= minimum; Max= maximum; ${ }^{\text {a }}$ Mesocuric curve accepted for values between -1.96 and +1.96.

Table 2. Pearson correlation between the dimensions of the Inventory of Motivation for the Regular Practice of Physical Activity - IMPRAF 54.

\begin{tabular}{|c|c|c|c|c|c|c|}
\hline & Health & Pleasure & Stress Control & Sociability & Competitiveness & Aesthetics \\
\hline Health & 1.00 & & & & & \\
\hline Pleasure & $0.63^{*}$ & 1.00 & & & & \\
\hline Stress Control & $0.51^{*}$ & 0.25 & 1.00 & & & \\
\hline Sociability & 0.20 & 0.09 & 0.44 & 1.00 & & \\
\hline Competitiveness & -0.01 & 0.38 & -0.13 & 0.16 & 1.00 & \\
\hline Aesthetics & 0.39 & $0.74 *$ & 0.10 & 0.20 & $0.69 *$ & 1.00 \\
\hline
\end{tabular}

Note: ${ }^{*} p<0.05$ with Bonferroni correction. 
and committed participations ${ }^{22}$. In addition to the theoretical elements described above, this discursive space provided the understanding that the way of thinking and acting in relation to sports injuries was supported by values, rules and conceptions that guided its construction ${ }^{25}$. When you think about the descriptors and stay tuned to each one of them, you can perceive how each participant saw himself in the world and his personal situation. In relation to the descriptor "motivation for physical activities", we highlight the following report:

"I get motivated and I fight for my own overcoming. I seek to advance beyond my physical and mental strength. Sometimes I think I'm made of iron..." (athlete 2)

Analyzing the conversation about "health" it was observed:

"Health is the priceless thing that this practice has brought me. I have friends, I am valued, I am seen, I am whole, I collaborate with the team and when I am injured everyone cares about me. What more could I want?..." (athlete 8)

When encouraged to talk about "emotions":

"When I was injured, I received a call every day from one or another of the girls on the team ... she always told what happened in the training sessions, what the coach said and suggested, what he said about me, and that support gives me strength to overcome the distance and pain. I was always very sensitive, but in moments of recovery the emotion I felt when I knew that I was someone important to my friends made me recover faster..." (athlete 2 )

In relation to the descriptor "group of friends":

"We had an excellent coach who taught us to respect each other. He never treated us as athletes, but always as people and these people he wanted to see grow ... then, we grew friends. You have no owner, you do not have a reservation, you have not injuried, you have not healed: you have friends..." (athlete 6)

When it comes to "physical-mental recovery":

"I think: if my head, my emotional, my projects are well, you can forget about me: nothing will knock me down. But when I hesitate, I am frightened, I am uncomfortable, then I fall, I dry up, I am a mess... my head controls everything. I've always been like this since I was a little girl..." (athlete 8)

The possibility of speaking about the "satisfaction of being well", of "being well looked and well taken care of", of "being welcomed":
"I live far from my family, I spend a week in training and in college... but when things are hard, when nothing works, when there is still an injury... if was not for the group and the coach I swear I would die. They give me strength, they push me forward and this fills me with satisfaction. I do not want to leave here any more..." (athlete 10)

This exercise of dialogue between the athletes made it possible to find similarities in the singularities of each person involved. It was an integrating and sharing space that certainly awakened to an understanding of the injury that occurred in sports practice and opened a path that could help in the conduction of the subject under study, both in the personal and professional life of the participants.

\section{DISCUSSION}

The reasons for the practice of physical activity should be known in order of priority, i.e., in each subject the reasons for practice will obey an order, thus there is a possibility of decisive collaboration of the individual in the practice of regular physical activity.

In the evaluated dimensions, it is noticed that several scores are given by the athletes demonstrating the meaning related to the particular variable. Representing subject's individualities and that several factors may be exerting influence at that time. In SDT there is no rule of how the subject will achieve success, but rather how such behavior can be regulated to achieve a satisfactory outcome. This theory is important and has been well accepted in the sporting context demonstrating the different motivational forms of various behavioral, affective and cognitive benefits ${ }^{26}$. The difference found between the dimensions of IMPRAF-54 can demonstrate that subjects are motivated in different ways, since some dimensions presented with greater intensity and others with less. The extrinsic motives may represent a greater or lesser degree of autonomy and of cognitive-intellectual liberty ${ }^{27}$. Thus, the greater the autonomy of the subject, the greater the degree of self-determination of the athlete. The Pleasure, Health and Sociability dimensions were highlighted in the results of this research, corroborating the findings of the research carried out with non-athletes ${ }^{8}$. It presented higher scores in the mentioned dimensions due to the conception about health and the practice of physical activity associated with the pleasure and maintenance of social contact ${ }^{8}$. These results were reinforced in the discussions of this article.

The main reason presented by the athletes in the present study was Pleasure. This dimension of the evaluation instrument may be related to the psychological satisfaction of the individual and that this is inserted in the group of friends and in society, developing well their cognitive and motor skills. When the Pleasure dimension is prioritized by the subject, they deals better with situations with stressful factors. This may 
explain the fact that the low scores presented in the stress control dimension ${ }^{27}$. It was observed that the Competitiveness dimension presented one of the smallest values, suggesting that athletes, even injured, did not bother to be or remain competitive at the moment, but emphasized well-being and recovery. In detailing each dimension, each item has its own specificities and influences. In some dimensions there was a great variation in the averages of their items, showing a great heterogeneity of the data. According to Barbosa ${ }^{28}$ each item must have correlation with its own dimension and there should be no negative correlations between an item and the total scale. Several factors influence the occurrence of injuries, but during the rehabilitation phase the external factor (family) has a very important support for a good result ${ }^{29}$. It is common that in the phases of the treatment of the injuries there is follow-up of professionals like doctors and physiotherapists, but in few studies the psychologist is quoted ${ }^{30}$. However, this professional should be present preparing the athletes for situations of confrontation.

Researches corroborates the findings of this study, demonstrating that athletes should present psychological skills for their development in sport ${ }^{21,29}$. A detailed evaluation and monitoring of the athlete's situation should continue throughout the sporting context, maintaining the relationship between professional and athlete that will facilitate the process of physical and psychological recovery.

In the second phase the quantitative result was confirmed by the qualitative one, in which the athletes allowed to dialogue about pleasure subjectively reaffirming this concept as a satisfaction of being well, being well seen in society, being well taken care of, feeling welcomed and fulfilled. In this way, it was possible to identify the sense of motivation proposed as a dynamic and permanent process, throughout life, allowing the singularly constructed cultural expression, in the handling and confrontation of these conditions ${ }^{25}$. It can be observed that the studied athletes were motivated to return to volleyball practice, even after suffering some type of injury. Among the motivational dimensions evaluated through the quantitative instrument used, Pleasure was the dimension that exerted the greatest influence for the return to the practice of the modality. This result was confirmed in the second phase of the study, which provided more reflections and allowed a greater self-knowledge of the sensations and feelings of the athletes themselves, since this subjectivity can not be only captured by objective instruments. The study evidenced possibilities of self-reflection and self-knowledge, that the human being has its limitations and fragilities and that the evaluated athletes presented their answers based on the values and the conceptions that were constructed during the life and may not change with the time ${ }^{2}$. In addition to this, the FG technique has made participants' interest in a broader discussion on the subject, opening up an subject reflective and critical space. The exercise of listening to oneself and the other members of the group was an element of awareness for them about their own conceptions.

\section{CONCLUSIONS}

Based on the objective of the present study and the results found, it can be concluded that the athletes were motivated to return to volleyball, even after suffering injury. It is possible to affirm that amateur athletes who are recovering from injuries are not focused on competition and that the main reasons for their return to practice are related to pleasure, health and sociability, although these motives varied in intensity according to with the individualities of each athlete. Among the limitations of the study we can mention the reduced number of amateur athletes participating in the research and the use of the IMPRAF-54 questionnaire in an exploratory way since its validation in different populations has yet to be developed. In the IMPRAF-54 study of Balbinotti \& Barbosa ${ }^{21}$, the authors suggest the need for new application and questionnaire validation studies with other sample groups as income and handicap athletes. When applying the inventory in the athletes of the present research it was noticed a great similarity in the results found in the study, however the sample was smaller and different. With this, we suggest at the end of this work a new sample search and perhaps a possible validation of the questionnaire for athletes.

Finally, when thinking about sports psychology, it is noted the importance of the professionals' performance in a meaningful way with injured athletes, helping their limitations and fragilities, thus providing a self-reflection, self-knowledge and adequate possibilities to overcome the injury, with the aid of physical and psychological rehabilitation. In addition, psychological rehabilitation does not depend only on the performance of the sports psychologist, but rather on a joint work of several professionals and especially the athlete, who will have a primary role in this recovery.

\section{AUTHOR'S CONTRIBUTION}

LBR: Data collection, introduction and discussion; IWT: Methodology and discussion; FR: Results and Results analysis; PCVR: Data collection and conclusion; AAM: Methodology and conclusion.

\section{CONFLICTS OF INTEREST}

The authors declare that there was no conflict of interests.

\section{AUTHOR DETAILS}

${ }^{2}$ Centro Universitário Adventista de São Paulo - UNASP, São Paulo-SP, Brazil. ${ }^{3}$ Universidade Estácio de Sá - UNESA, São Paulo-SP, Brazil. ${ }^{4}$ Universidade Federal de Lavras - UFLA, Lavras-MG, Brazil.

\section{REFERENCES}

1. Weinberg RS, Gould D. Fundamentos da psicologia do esporte e do exercício. ArtMed: Porto Alegre, 2001.

2. Blanchard CM, Mask L, Vallerand RJ, Sablonnière R, Provencher $P$. Reciprocal relationships between contextual and situational motivation in a sport setting. Psychol Sport Exerc.2007;8(5):854-873. 
3. Calvo TG, Cervelló E, Jiménez R, Iglesias D, Murcia JAM. Using selfdetermination theory to explain sport persistence and dropout in adolescent athletes. Span J Psychol.2010;13(2):677-684.

4. Ryan RM, Deci EL. Intrinsic and Extrinsic Motivations: classic definitions and new directions. Contemp Educ Psychol.2000;25(1):54-67.

5. Ryan RM, Fredrick CM, Lepes D, Rubio N, Sheldon KM. Intrinsic Motivation and Exercise Adherence. Int J Sport Psychol.1997;28(4):335-354.

6. Chatzisarantis NL, Biddle SJHJ, Meek GA, Chatizasarantz NLD, Biddle SJHJ, Meek GA. A self-determination theory approach to the study of intentions and the intention - behaviour relationship in children's physical activity. Br J Health Psychol.1997;2(4):343-360.

7. Guimarães SÉR, Boruchovitch E. O Estilo Motivacional do Professor e a Motivação Intrínseca dos Estudantes: Uma Perspectiva da Teoria da Autodeterminação. Psicol Reflexão e Crítica.2004;17(2):143-150.

8. Balbinotti MAA, Zambonato F, Barbosa MLL, Saldanha RP, Balbinotti CAA. Motivação à prática regular de atividades físicas e esportivas: um estudo comparativo entre estudantes com sobrepeso, obesos e eutróficos. Motriz.2011;17(2):384-394.

9. Serour M, Alqhenaei H, Al-Saqabi S, Mustafa A, Ben-Nakhi A. Cultural factors and patients adherence to lifestyle measures. Britishi J Gen Pract.2007;57(537):291-295.

10. Machado AA, Brandão MRF. Performance esportiva de adolescentes: influências psicológicas externas. Motriz.2006;12(3):262-268.

11. Veloso S, Pires AP. A Psicologia das lesões esportivas: importância da intervenção psicológica. Rev Port Fisioter no Desporto.2007;1(21):38-47.

12. Brandão MRF, Machado AA. Coleção Psicologia do Esporte e do Exercício: Aspectos Psicológicos do Rendimento Esportivo. Atheneu:São Paulo,2008.

13. Ribeiro F. Incidência de lesões no voleibol: acompanhamento de uma época esportiva. Arq Fisioter.2007;1(3):29-34.

14. Buceta JM. Psicología y Salud: control del estrés y trastornos asociados. Dykinson:Madrid,1995.

15. Rebustini F, Calabresi CAM, Silva AB, Machado AA. Efeito imediato de duas intensidades de treinamento sobre os estados de humor em jovens voleibolistas do sexo feminino. Lect Educ Física y Deport.2005;10(80):1.

16. Kozinets RV. Netnografia: Realizando pesquisa etnográfica online. Penso:Porto Alegre,2014.
17. Sharp JLJL, Mobley C, Hammond C, Withington C, Drew S, Stringfield $S$ et al. A mixed methods sampling methodology for a multisite case study. J Mix Methods Res.2012;6(1):34-54.

18. Tashakkori A, Creswell JW. Editorial: The new era of mixed methods. J Mix Methods Res.2007;1(1):3-7.

19. Fakis A, Hilliam R, Stoneley H, Townend M. Quantitative analysis of qualitative information from interviews: a systematic literature review. J Mix Methods Res.2014;8(2):139-161.

20. Creswell JW, Clark VLP. Pesquisa de métodos mistos. 2nd ed. Penso:Porto Alegre,2013.

21. Balbinotti MAA, Barbosa MLL. Análise da consistência interna e fatorial confirmatório do IMPRAFE-126 com praticantes de atividades físicas gaúchos. Psico-USF.2008;13(1):1-12.

22. Bomfim LA. Grupos Focais: conceitos, procedimentos e reflexões baseadas em experiências com o uso da técnica em pesquisas de saúde. Physis Rev Saúde Coletiva.2009;19(3):777-796.

23. Kind L. Notas para o trabalho com a técnica de grupos focais. Psicol em Ver.2005; 10(5):124-136.

24. Field A. Descobrindo a estatística usando o SPSS. Bookman:São Paulo,2009.

25. Hagger M, Chatzisarantis N. Self-determination theory and the psychology of exercise. Int Rev Sport Exerc Psychol.2008;1(1):79-103.

26. Fernandes HM, Raposo JV. Continnum de Auto-Determinação: validade para a sua aplicação no contexto desportivo. Estud Psicol.2005;10(3):385-395.

27. Balbinotti MAA, Capozzoli CJ. Motivação à prática regular de atividade física : um estudo exploratório com praticantes em academias de ginástica. Rev Bras Educ Física e Esporte.2008;22(1):63-80.

28. Barbosa MLL. Propriedades métricas do inventário de motivação à prática de atividade física e/ou esporte (IMPRAF-126). [Dissertação de Mestrado em Ciências do Movimento Humano]. Porto Alegre: Unversidade Federal do Rio Grande do Sul. Progrma de Pós- Graduação em Ciências do Movimento Humano;2006.

29. Nunes CRO, Jaques $M$, Almeida FT, Heineck GIU. Processos e intervenções psicológicas em atletas lesionados e em reabilitação. Rev Bras Psicol do Esporte.2010;3(4):130-146.

30. Santos SGG, Piucco T, Reis DCC. Fatores que interferem nas lesões de atletas amadores de voleibol. Rev Bras Cineantropometria e Desempenho Hum.2007;9(2):189-195. 